\title{
ESTUDO DA DEGRADAÇÃO OXIDATIVA DE RESÍDUO DE LEVEDURA EMPREGADO COMO BIOSSORVENTE PARA CORANTE TÊXTIL
}

\author{
A. R. IMAMURA ${ }^{1}$, K. RIBEIRO ${ }^{1}$ e G. LABUTO $^{1}$ \\ ${ }^{1}$ Grupo de Análises Químicas Aplicadas, Universidade Federal de São Paulo \\ E-mail para contato: augusto_r.7@hotmail.com
}

\begin{abstract}
RESUMO - A contaminação de águas por efluentes industriais é uma preocupação mundial sendo a indústria têxtil um dos maiores consumidores e poluidores da água. A biossorção tem sido empregada com sucesso para a remoção célere e eficiente de corantes têxteis de meios aquosos, permitindo a disponibilização rápida da água tratada para reuso. Contudo, após sorção, os materiais biossorventes tem como destino final o aterro sanitário ou a incineração, soluções de custos questionáveis e não ambientalmente amigáveis. O uso exclusivo de processos oxidativos avançados (POA) para o tratamento de efluentes têxteis também tem sido utilizado. Porém, em larga escala, o custo e tempo necessário para a disponibilização da água tratada para reuso e os grandes volumes a serem tratados são limitantes destes processos. A associação da biossorção e POA pode ser um caminho interessante para o tratamento de efluentes têxteis. O presente trabalho empregou processos foto-Fenton para o tratamento de resíduo de biomassa de levedura seca proveniente da indústria sucroalcooleira após sorção de corante têxtil reativo Red-FNR (Cibacrom, Huntusman, EUA). O processo foto-Fenton mostrou-se eficaz para degradação de resíduo sólido de levedura com remoção de $61,2 \%$ da massa em 45 minutos.
\end{abstract}

\section{INTRODUÇÃO}

Dentre as indústrias mais poluidoras, a têxtil ganha destaque pelo elevado consumo de água e a exposição deste bem de direto da humanidade a uma variedade de substâncias que apresentam características químicas e toxicológicas tão diversas que dificultam o estabelecimento de uma única forma de tratamento para os efluentes gerados (Kant, 2012).

Aproximadamente 52\% das fibras têxteis são compostas de algodão e a produção destas fibras coloridas contribui bastante para a geração de efluentes pigmentados com corantes reativos, estes apresentam substâncias potencialmente danosas aos seres vivos. Em vista do potencial tóxico dos efluentes têxteis, surgiram normas legais que imputam à indústria têxtil a responsabilidade pelo controle e tratamento de seus efluentes, levando estas à busca de alternativas para minimizar seus impactos.

Para atender a legislação a indústria têxtil tem empregado largamente processos envolvendo micro-organismos no tratamento de seus efluentes, utilizando lodo ativado ou micro-organismos biologicamente ativos para a degradação, interconversão, ou acumulação de espécies contaminantes (Sangchul et al., 2005). 
Tais tratamentos são lentos e envolvem o profundo conhecimento metabólico do organismo empregado, a manutenção de suas condições ideais de ação, a sua toxicidade, já que em alguns casos, o descarte feito em áreas impróprias pode provocar transtornos ambientais gravíssimos, além de gerar enormes quantidades de resíduos sólidos a serem manejados (Sponza, 2000).

A biossorção surge como uma alternativa interessante, uma vez que se vale de microrganismos ou outro material de origem biológica inativos, atuando em um processo físico-químico, análogo à convencional tecnologia de troca iônica (Gadd, 2009). Apesar de sua eficiência, os destinos finais dos bissorventes são a incineração e o depósito em aterros sanitários, estes são agressivos ao meio ambiente e às vezes podem possibilitar a (re) introdução dos contaminantes removidos ou de seus derivados.

Dessa maneira, os processos oxidativos avançados, os quais contemplam a conversão dos resíduos orgânicos em $\mathrm{CO}_{2}$ e $\mathrm{H}_{2} \mathrm{O}$, em associação com a biossorção pode ser um caminho considerável para o tratamento de efluentes têxteis. Tal união permitiria a remoção acelerada dos contaminantes do efluente e consequentemente a rápida disponibilidade da água para reuso, acompanhado de tratamento do bissorvente impregnado com o contaminante por POA em volumes menores.

\subsection{Processos Fenton e foto-Fenton}

O processo Fenton baseia-se na combinação de peróxido de hidrogênio e íons ferrosos em meio ácido, gerando radicais hidroxilas que atacam compostos orgânicos. A adição da luz UV sobre o processo é uma poderosa ferramenta no tratamento, assim este processo é conhecido por Foto-Fenton. As reações que envolvem o processo estão listadas abaixo.

$$
\begin{array}{lr}
\mathrm{Fe}^{2+}{ }_{a q}+\mathrm{H}_{2} \mathrm{O}_{2} \rightarrow \mathrm{Fe}^{3+}{ }_{a q}+\mathrm{OH}^{-}+\mathrm{HO}^{\cdot} & \mathrm{k}_{1}=53-76 \mathrm{M}^{-1} \mathrm{~s}^{-1} \\
\mathrm{Fe}^{3+}+\mathrm{H}_{2} \mathrm{O}_{2}+\mathrm{H}_{2} \mathrm{O} \rightarrow \mathrm{Fe}^{2+}+\mathrm{H}_{3} \mathrm{O}^{+}+\mathrm{HO}_{2} & \mathrm{k}_{2}=1-2 \times 10^{-2} \mathrm{M}^{-1} \mathrm{~s}^{-1} \\
\mathrm{Fe}^{3+}{ }_{a q}+\mathrm{H}_{2} \mathrm{O}+h \mathrm{~h} \rightarrow \mathrm{Fe}^{2+}{ }_{a q}+\mathrm{H}^{+}+\mathrm{HO}^{\cdot} & \Phi\left(+\mathrm{Fe}^{2+}\right)=0,195(310 \mathrm{~nm})
\end{array}
$$

A reação Fenton térmica (Equação 1) é eficiente na remoção de poluentes orgânicos, porém requer quantidades estequiométricas de $\mathrm{Fe}^{2+}$, sendo retardada após a conversão completa do $\mathrm{Fe}^{2+}$ ao $\mathrm{Fe}^{3+}$. A reação representada na Equação 2 é muito mais lenta que a representada na Equação 1 e determina a taxa global do processo. No intervalo de $\mathrm{pH}$ entre 2,8 e 3,2, no qual ocorre a reação de Fenton, a espécie de $\mathrm{Fe}^{3+}$ predominante em solução aquosa é a $\mathrm{Fe}(\mathrm{OH})^{2+}$, a qual pode absorver luz em comprimentos de onda entre 280-405 nm, regenerando o $\mathrm{Fe}^{2+}$ no sistema de acordo com a Equação 3. Deste modo, a reação Fenton passa a ser designada de foto-Fenton ou Fenton foto-assistida, intensificando a degradação de poluentes orgânicos (Pignatello et al., 2006, Nogueira et al, 2012).

\section{OBJETIVO}

Promover a degradação oxidativa de biomassa de levedura empregada como biossorvente do corante reativo Red-FNR (Cibacrom, Huntusman, USA) após sorção, visando a mineralização completa. 


\section{MATERIAIS E MÉTODOS}

As amostras do material utilizadas neste trabalho são a biomassa de levedura seca (BL) proveniente da indústria sucroalcooleira empregada previamente para a sorção do corante têxtil reativo Red-FNR (Cibacrom, Huntusman, USA). Os estudos de sorção foram realizados adicionando-se alíquotas de $5 \mathrm{~mL}$ de solução $0,5 \% \mathrm{~m} \mathrm{v}^{-1}$ do corante vermelho FNR (Cibacrom, Huntusman, EUA), preparadas sob as condições do meio de tingimento (30 $\mathrm{g} \mathrm{L}^{-1}$ $\mathrm{NaCl}$ e $12 \mathrm{~g} \mathrm{~L}^{-1} \mathrm{Na}_{2} \mathrm{CO}_{3}$ ) foram adicionas a cerca de $2 \mathrm{~g}$ de $\mathrm{BL}$, previamente umedecido com água destilada deionizada, para não mascarar o efeito da hidratação sobre a sorção. Após agitação em mesa agitadora $(100 \%, 20 \mathrm{~min}$.) e centrifugação (10.000 rpm, 4 min.), o sobrenadante de corante foi colocado em contato com uma nova porção de $2 \mathrm{~g}$ de BL, previamente umedecida com água. O processo de sorção sequencial foi repetido até que a quantidade de corante observada visualmente no adsorvente fosse impossível de ser observada (6 vezes). A Figura 1 evidencia as diferentes porções de BL empregada após sorção sequencial.

A biomassa de levedura contendo corante adsorvido (BL-C) utilizada nos estudos de degradação oxidativa corresponde a proveniente do primeiro contato do corante com o biossorvente, identificada na Figura 1 como S1. A amostra S1 entrou em contato com o corante têxtil e qual removeu em torno de $99 \%$ do corante da solução, o que correspondeu ao equivalente a $10,26 \pm 0,05 \mathrm{~g} \mathrm{Kg}^{-1}$ de corante/biomassa.

Figura 1. Biomassa de levedura contendo corante adsorvido (BL-C) provenientes do estudo de sorção sequencial de corante vermelho Red-FNR (Huntusman, USA), S1: BL após contato com o corante; S2: BL após contato com solução remanescente do tratamento S1; S3:

BL após contato com solução remanescente do tratamento S2 e; S4: BL após contato com solução remanescente do tratamento $\mathrm{S} 3$.

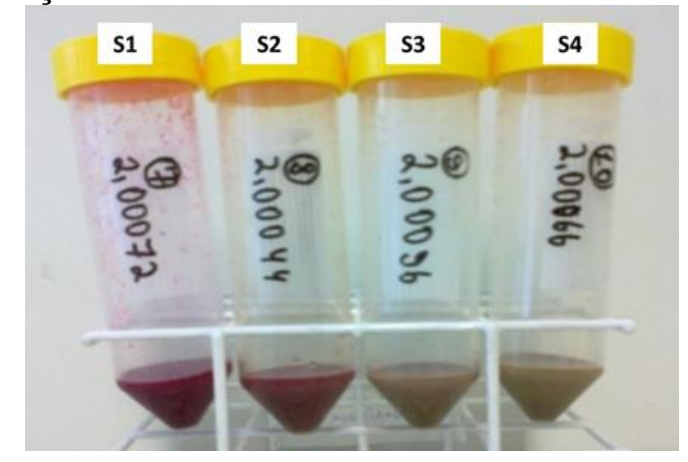

Os estudos de degradação oxidativa de BL contendo corante adsorvido (BL-C) foram conduzidos em batelada em um pequeno reator, o esquema utilizado apresenta-se na Figura 2. Partindo de um planejamento fatorial do tipo estrela blocado na potência da lâmpada UV, foram utilizadas as potências de 30 e $80 \mathrm{~W}$. Para os 32 experimentos realizados foram variados três parâmetros: tempo, a concentração de peróxido de hidrogênio e do íon ferroso.

A Tabela 1 representa os níveis escolhidos para as variáveis codificadas, assim como seus valores reais, para o planejamento composto central. 
Figura 2 - Reator utilizado nos experimentos.

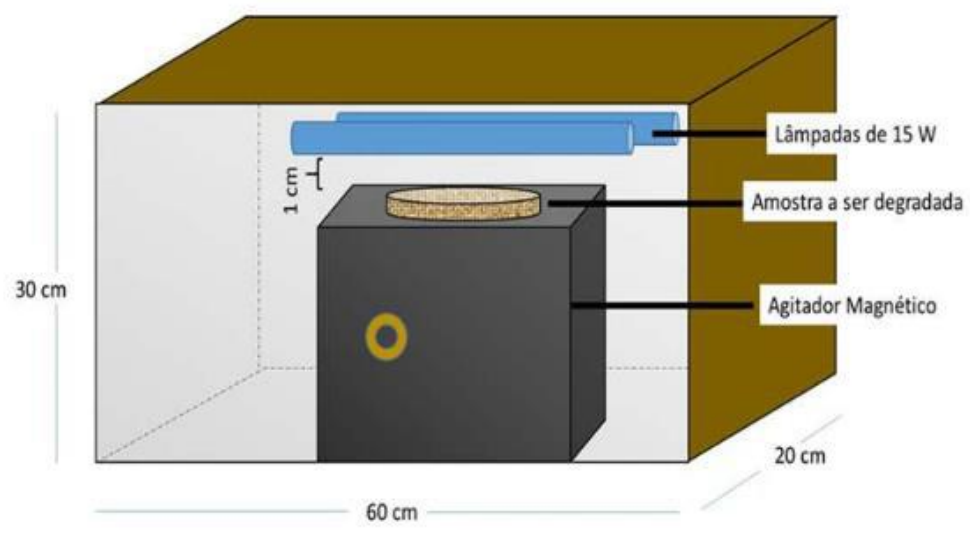

Tabela 1 - Níveis das variáveis estudadas

\begin{tabular}{|c|c|c|c|}
\hline Variáveis & $\mathbf{- 1}$ & $\mathbf{0}$ & $\mathbf{+ 1}$ \\
\hline $\mathrm{UV}(\mathrm{W})$ & 30 & - & 80 \\
\hline$\left[\mathrm{H}_{2} \mathrm{O}_{2}\right]\left(\mathrm{mg} \mathrm{L}^{-1}\right)$ & 400 & 600 & 800 \\
\hline$\left[\mathrm{Fe}^{+2}\right]\left(\mathrm{mg} \mathrm{L}^{-1}\right)$ & 20 & 30 & 40 \\
\hline Tempo $(\mathrm{min})$ & 30 & 45 & 60 \\
\hline
\end{tabular}

As soluções de $\mathrm{Fe}^{2+}$ e $\mathrm{H}_{2} \mathrm{O}_{2}$ são preparadas para as concentrações desejadas e levadas para um conjunto contendo $25 \mathrm{mg}$ de BL, o pH dessa solução é ajustada para próximo de 3 e é levado para o reator, o qual já contém a lâmpada UV na potência desejada, e por meio de uma chapa agitadora, a solução permanece no reator pelo tempo desejado.

\section{RESULTADOS E DISCUSSÃO}

Inicialmente foi realizada a análise conforme previsto para composto central blocado na intensidade de radiação da lâmpada. O resultado da análise dos efeitos das variáveis teve um ajuste com $\mathrm{R}^{2}=0,8746$, que não representa um ajuste aceitável do modelo matemático aos resultados experimentais. Deste modo a análise estatística para o planejamento composto central foi realizada de modo não blocado, isto é a variável radiação UV que determinava os blocos dos experimentos foi incluída como variável dependente, torando-se o conjunto dessas: lâmpada empregada para radiação $\mathrm{UV}, \mathrm{H}_{2} \mathrm{O}_{2}, \mathrm{Fe}^{2+}$ e tempo. Importante salientar que para a variável UV havia dois níveis disponíveis, 30 e $80 \mathrm{~W}$.

Nesta nova análise, os resultados mostraram que a componente quadrática é significativa e o erro padrão puro foi de 0,66 para um efeito médio do planejamento de 41,80 e $\mathrm{R}^{2}=0,9699$, o que reflete o ajuste do modelo matemático aos dados experimentais.

Realizando a análise de Pareto para as 4 variáveis e para um nível de significância de 95\% (Figura 3) podemos notar que a variável $\mathrm{Fe}^{2+}$ tem maior significância quando o normalmente esperado é que a variável $\mathrm{H}_{2} \mathrm{O}_{2}$ tenha maior significância já que é o reagente limitante consumido na reação. Deste modo podemos supor que o $\mathrm{Fe}^{2+}$, já em baixa concentração, pode ter sofrido alguma precipitação durante a reação de degradação, passando a reagente limitante. $\mathrm{O}$ fato é que o $\mathrm{Fe}^{2+}$ é o componente mais significante no processo estudado, sendo, portanto, o maior controlador da velocidade de reação. 
Figura 3 - Pareto dos efeitos padronizados e Valores observados x Preditos.
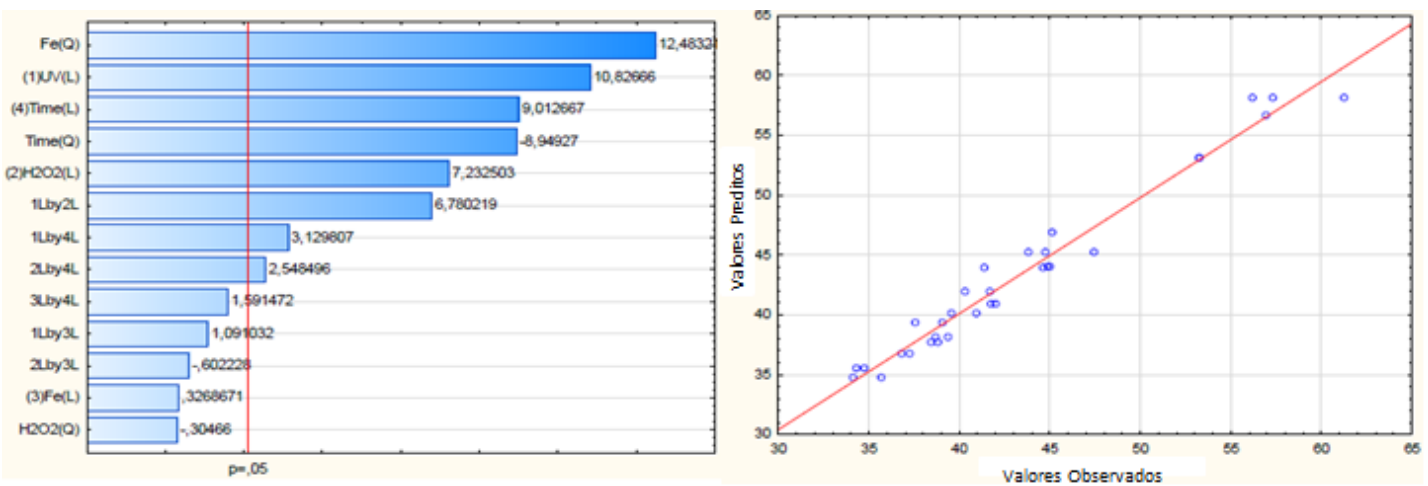

A variável potência de radiação UV, tratada como variável em dois níveis mostrou uma significância importante e de acordo, já que quanto maior a potência irradiada maior o número de fótons disponíveis para o processo de geração de $\bullet \mathrm{OH}$ e regeneração de $\mathrm{H}_{2} \mathrm{O}_{2}$ no meio. $\mathrm{O}$ $\mathrm{H}_{2} \mathrm{O}_{2}$, como esperado, também mostrou efeito significativo. A variável tempo mostrou significância coerente para o termo linear, mas para o termo quadrático mostrou efeito negativo. Isso significa que esta variável deverá ser redimensionada para trabalhos futuros.

É importante destacar que foi verificado o bom ajuste entre os valores preditos e os observados pelo modelo, como mostrado na Figura 3. Tal fato reflete que o modelo teórico está bem ajustado aos dados experimentais. Assim, é possível a partir disto, construir superfícies de resposta que indicam qual a melhor condição de trabalho, as mesmas estão indicadas na Figura 4.

Figura 4 - Superfícies de Resposta.
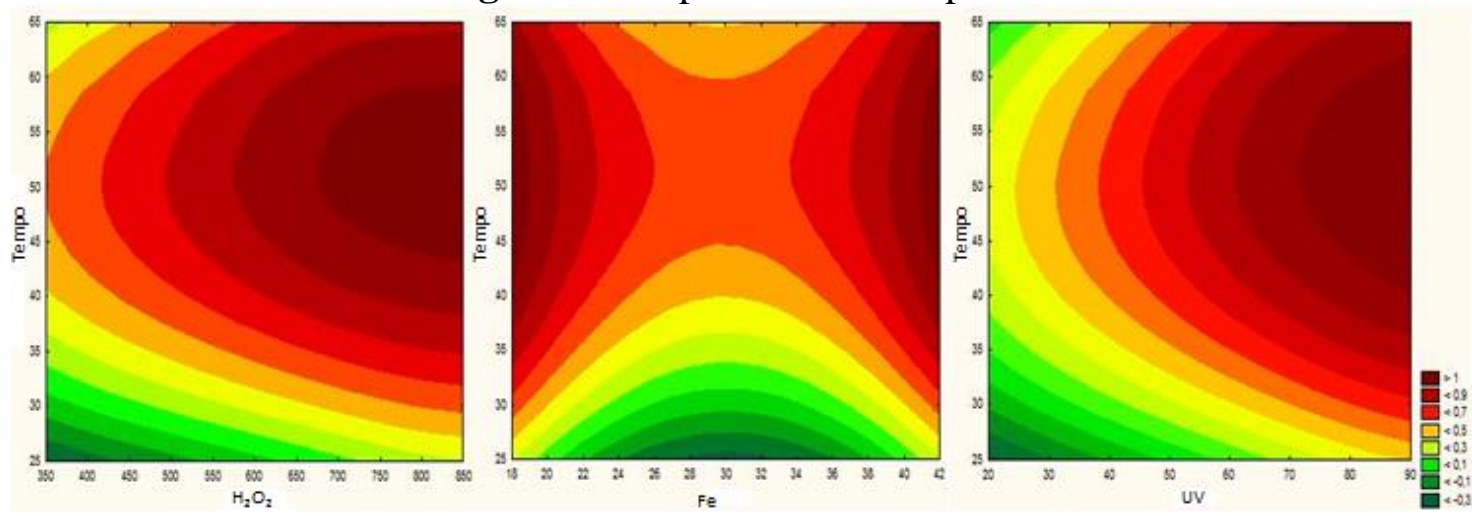

Ao analisarmos as superfícies de resposta mostradas na Figura 4, nota-se que as melhores condições encontradas para os experimentos ao longo do tempo são concentrações altas concentrações de peróxido de hidrogênio, concentrações baixas ou altas do íon ferroso e maior nível de radiação UV que já era esperado, pois com um maior número de fótons, seguindo a Equação 3, há a maior formação de hidroxila.

Para estes resultados a melhor condição foi de $61,22 \%$ de remoção de massa após 45 minutos de reações do processo foto-Fenton. Não foi encontrado um ponto ótimo para este conjunto de experimentos. 


\section{CONCLUSÃO}

A partir dos resultados dos 32 experimentos foi possível constatar uma máxima degradação de massa de 61,22\% em $45 \mathrm{~min}$. empregando $600 \mathrm{mg} / \mathrm{L}$ de $\mathrm{H}_{2} \mathrm{O}_{2}$ e $40 \mathrm{mg} / \mathrm{L}$ de $\mathrm{Fe}^{2+}$. Desta forma, as melhores condições encontradas, com base neste procedimento experimental não permitiram determinar um ponto ótimo de degradação porque o estudo da degradação do biossorvente sugere uma dependência não linear das respostas sobre a variável dependente. Entretanto foi observado um bom ajuste entre os valores preditos e os observados pelo modelo. Assim, o processo foto-Fenton mostrou-se eficaz para degradação de resíduo sólido de levedura necessitando maiores estudos para determinar as melhores condições experimentais e operacionais.

\section{AGRADECIMENTOS}

Os autores agradecem ao grupo do laboratório LENCA pelo fornecimento do espaço e materiais para a realização de alguns experimentos e a FAPESP (projeto no 2016/20551-0 e 2016/0627-1).

\section{REFERÊNCIAS}

BAUER, R., The photo-Fenton reaction and the TiO2/UV process for waste water treatment novel developments, Catalysis Today, 1999, 53, 131-144.

GADD, G.M. Fungi and Yeast for Metal Accumulation in Microbial Mineral Recovery in Environmental Biotechnology, McGraw Hill, pp. 249-275, 1990.

KANT, R. Textile dyeing industry an environmental hazard, Natural Science, 2012, 4, 22-26.

NOGUEIRA, K. R. B., NASCIMENTO, C. A. O., GUARDANI, R., TEIXEIRA, A. C. S. C. Feasibility Study of a Solar Reactor for Phenol Treatment by the Photo- Fenton process in Aqueous Solution. Chem. Eng. Technol. 35, 2125-2132, 2012.

NATARAJAN, K.A.; Removal of metal ions using on industrial biomass with references to environmental control. International Journal of mineral processing, Amsterdam, 1998, 53, 107-120.

PIGNATEllo, J. J.; OLIVEROS, E.; MACKAY, A. Advanced oxidation processes for organic contaminant destruction based on the Fenton reaction and related chemistry. Crit. Rev. Env. Sci. Technol., v. 36, p. 1-84, 2006.

SANGCHUL, Rho; AN, Nan Hee; AHN, Dae Hee; et al PCR-T-RFLP analyses of bacterial communities in activated sludges in the aeration tanks of domestic and industrial wastewater treatment plants.. Journal of Microbiology and Biotechnology, 2005, 15, 287-295.

SPONZA, D. T. Necessity of toxicity assessment in Turkish industrial discharges (examples from metal and textile industry effluents), Environmental monitoring and assessment, 2000, 73, 41-66. 